\title{
Nanochannels for Supramolecular Organisation of Dyes
}

\author{
André Devauxa ${ }^{\mathrm{a}}$ Katsiaryna Lutkouskayaa ${ }^{\mathrm{a}}$, Gion Calzaferriª, Le-Quyenh Dieub \\ Dominik Brühwiler ${ }^{\mathrm{b}}$, Luisa De Colac ${ }^{\mathrm{c}}$, and Tomás Torres ${ }^{\mathrm{d}}$
}

\begin{abstract}
The supramolecular organisation of molecules, complexes or clusters is a fruitful concept for the design of systems exhibiting specific macroscopic properties. The encapsulation of guest species into the pores or channels of host materials presents a challenging approach to the preparation of novel chemical and optical materials. Zeolite $L$ has been shown to be an ideal host for the supramolecular organisation of organic dyes. A new hierarchy of structural ordering can be achieved by either arranging the zeolite $L$ crystals into densely packed, oriented monolayers or by interfacing them to the environment via molecules bound to the edges of the crystals. These concepts are reviewed here, as well as some potential applications.
\end{abstract}

Keywords: Energy transfer · Host-guest materials · Luminescence $\cdot$ Supramolecular $\cdot$ Zeolite L

\section{Introduction}

The properties and reactivity of molecules, complexes and clusters in confined space have been studied for over 50 years. ${ }^{[1,2]}$ In most of these studies, the host materials were synthetic zeolites, probably due to the well-defined, robust frameworks ${ }^{[3]}$ and their use in many industrial applications. ${ }^{[4]}$ Host materials exhibiting less well-defined frameworks but otherwise interesting properties, such as cyclodextrins ${ }^{[5]}$ and, more recently, mesoporous materials ${ }^{[6]}$ or organic

\footnotetext{
${ }^{*}$ Correspondence: Prof. Dr. G. Calzaferri ${ }^{\mathrm{a}}$

Tel.: + 41316314226

Fax: + 41316313994

E-Mail: gion.calzaferri@iac.unibe.ch

aDepartment of Chemistry and Biochemistry

University of Bern, Freiestrasse 3

$\mathrm{CH}-3012$ Bern

bInstitute of Inorganic Chemistry

University of Zürich, Winterthurerstrasse 190

$\mathrm{CH}-8057$ Zürich

cPhysikalisches Institut

Westfälische Wilhelms-Universität Münster,

Mendelstrasse 7

D-48149 Münster

dDepartamento de Quimica Orgánica

Universidad Autónoma de Madrid, Cantoblanco

E-28049 Madrid
}

zeolites $^{[7]}$ have been investigated in order to increase the variety of host-guest systems. Studies of molecules inserted into the onedimensional channels of AlPO-5 and zeolite L lead to the conclusion that host-guest materials with highly anisotropic optical properties can be prepared..$^{[8-10]}$

Based on preliminary experimental results ${ }^{[11,12]}$ and model calculations, ${ }^{[13]}$ we have designed an antenna system for the transport and trapping of electronic excitation energy that mimics the antenna system of green plants. These ideas, described in more detail elsewhere, ${ }^{[14]}$ turned out to be very fruitful. Our research was mainly focussed on zeolite L, as it is currently the only host available in a sufficiently large size regime, namely from $30 \mathrm{~nm}$ up to $10^{\prime} 000$ $\mathrm{nm}$, where the morphology of the crystals can be tuned to some extent. ${ }^{[15]}$ However, the general concept of highly organised zeolite-guest systems can in principle be applied to other host materials. Mesoporous silica MCM-41 is particularly promising in this regard, as it features a hexagonal array of one-dimensional channels and can be synthesized in the form of particles, fibres or thin films. ${ }^{[16]}$ With a tuneable pore diameter between 2 and $10 \mathrm{~nm}$, inclusion of large guest species such as phthalocyanines becomes possible, ${ }^{[17]}$ while surface silanol groups allow for the generation of defined functional group distributions on external and internal surfaces.[18]

The properties of zeolite $\mathrm{L}$ and the methods for the insertion of dyes either by ion exchange or by gas phase adsorption have been reviewed recently. ${ }^{[19]}$ Important steps in this research were the invention of the stopcock principle, ${ }^{[20]}$ the discovery of quasi 1-D energy transfer, [21] the development of methods to prepare unidirectional energy transfer material[22,23] and finding ways to create materials fully transparent in the visible range. ${ }^{[24]}$ The latter is important, since zeolite crystals exhibit considerable light scattering due to their size and refractive index between 1.4 and 1.5. With these tools in hand, one is now capable of designing and preparing a respectable variety of highly organised systems, some of which are illustrated in Fig. 1.

Zeolite $\mathrm{L}$ is the only microporous material currently available that allows the realisation of all these organisational patterns. These systems are highly ordered and exhibit useful properties for the design and preparation of novel photonic devices. In the next sections, we will review some of these properties along with examples of materials under investigation.

\section{Optically Anisotropic Energy Transfer Materials}

The structural formulas and corresponding abbreviations of dyes used in the preparation of the materials discussed in this work are given in Fig. 2. For other dyes which have been inserted into zeolite $\mathrm{L}$ see e.g. Tables 1 and 2 of ref. [19b].

Depending on shape and size, dyes can be organised inside the channels of zeolite $\mathrm{L}$ in different ways. Information on how they are oriented can be obtained either 


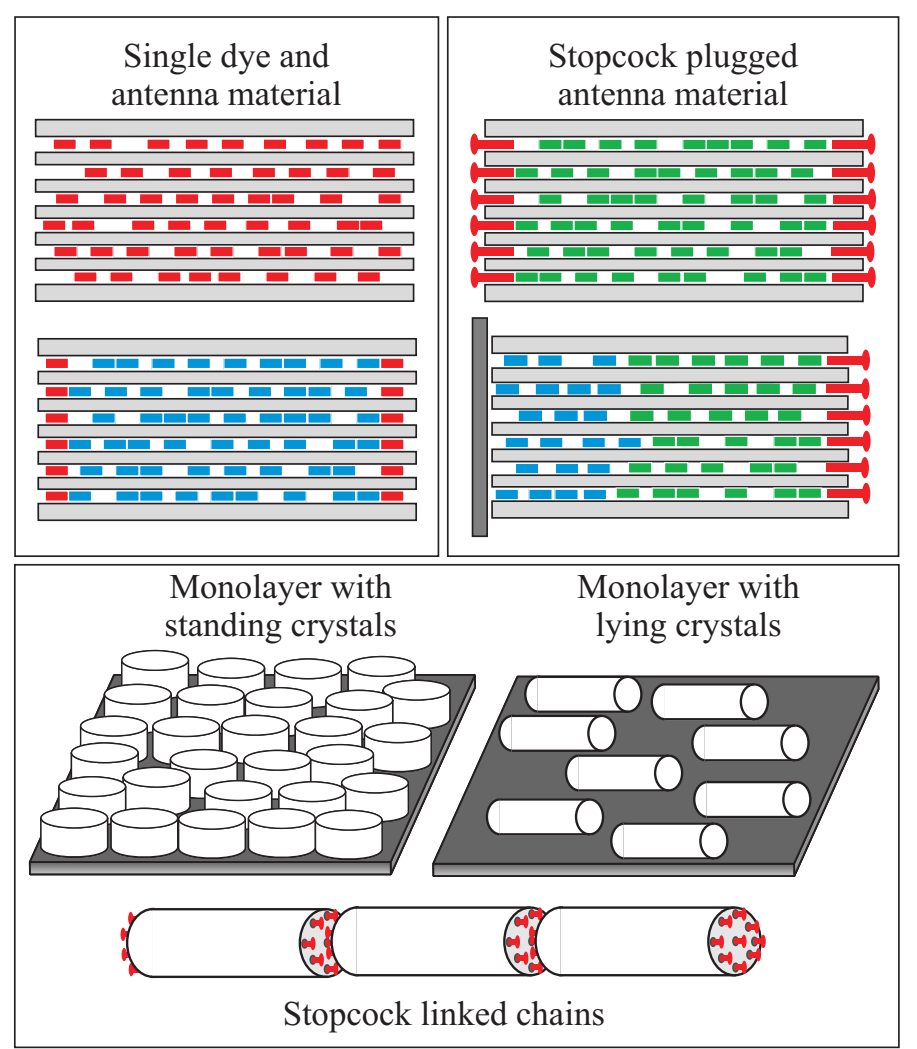

Fig. 1. Schematic representations of materials fulfilling the criteria of different stages of supramolecular organisation. All materials shown here have been successfully prepared. Top left: Single dye and antenna materials are obtained by either loading zeolite crystals with one kind of dye (top) or by the consecutive insertion of different dye molecules (bottom). Top right: Stopcockplugged antenna material obtained by modifying either bidirectional (top) or monodirectional (bottom) antenna materials with specific closure molecules, called stopcocks. Bottom: Organisation of zeolite $L$ crystals. Oriented monolayers of either standing or lying zeolite $L$ crystals on a substrate and a chain of crystals linked by the interaction between the stopcocks located at the channel entrances.

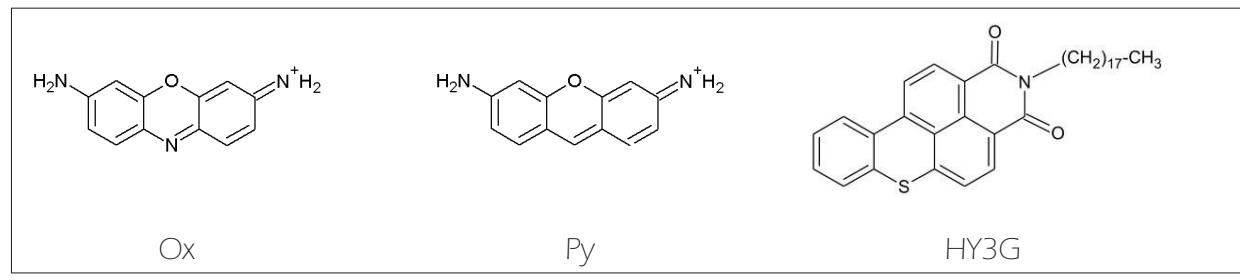

Fig. 2. Structural formulas of dyes used in this work

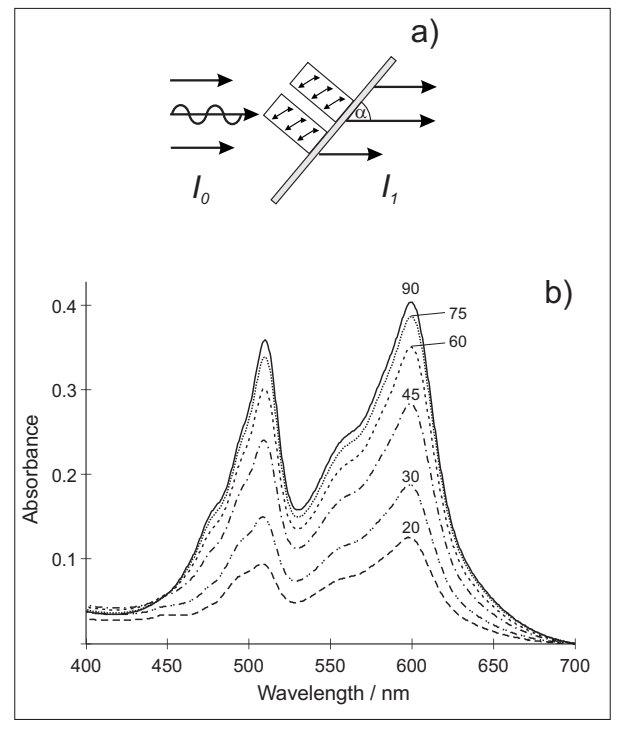

Fig. 3. Angle-dependent absorption spectra of a Py,Ox-zeolite L monolayer. a) Schematic representation of the measurement situation. b) Absorption spectra of a Py,Ox-zeolite L monolayer measured at angles $\alpha$ from $20^{\circ}$ to $90^{\circ}$. The numbers correspond to values of the angle $\alpha$. through polarised fluorescence microscopy on single crystals or by measuring the angledependent absorption spectra of a zeolite monolayer. A Py,Ox-zeolite L sample will be used to demonstrate the latter method. The measurement method is explained in Fig. 3a, where the dye-loaded monolayer is represented by two single crystals. The absorptivity depends on $\alpha$, defined as the angle between the incident light beam and the monolayer support, and on the orientation of the inserted dyes. The measured angle dependent absorption spectra are shown in Fig. 3b. The spectra were corrected for increased absorption path length as described previously. ${ }^{[25]}$ Absorptivity is highest for $\alpha$ $=90^{\circ}$, since the transition dipole moments of these dyes are organised in a cone-shaped distribution with an half-opening angle of about $72^{\circ} \cdot{ }^{[10,26]}$

\section{Stopcock Molecules}

The channel ends of zeolite $\mathrm{L}$ can be modified by specific closure molecules, which can only partly enter the channels. Such stopcock molecules consist typically of a head and a tail, as shown at the top of Fig. 4. Due to size restrictions, only the tail can enter the channel. ${ }^{[14]}$ Depending on the type, stopcocks can be bound either by physisorption (type I), by electrostatic interaction (type II) or by covalent bonding (type III). Fig. 4 summarises a selection of stopcocks successfully used so far. All N-hydroxysuccinimidyl ester (NHS) derivatives were covalently bound by first selectively modifying the channel entrances with alkoxysilane derivatives sporting a protected amino group. ${ }^{[27]}$ After removal of the protecting group, the amino groups at the zeolite surface can bind the NHS derivatives.

Since these molecules are located at the interface between the interior of a zeolite $\mathrm{L}$ crystal and the surroundings, they can be considered as mediators for communication between dye molecules inside the nanochannels and objects outside of the crystals. Fluorescent stopcocks can be used to extract or inject electronic excitation energy into or from the zeolite L crystals by fluorescence radiationless resonance energy transfer (FRET). ${ }^{[20 b, 39]}$ Stopcock molecules can also prevent penetration of small molecules such as oxygen and water or hinder encapsulated dye molecules from leaving the channels. We wish the communication between the exterior and the interior to be efficient and spatially well controlled. Therefore, the method for sequential modification of the channel entrances described in ref. [27] is an effective and flexible way to realise such an interfacing.

In the upper part of Fig. 5, a Van der Waals model illustrates the way a metal complex stopcock is reversibly adsorbed 

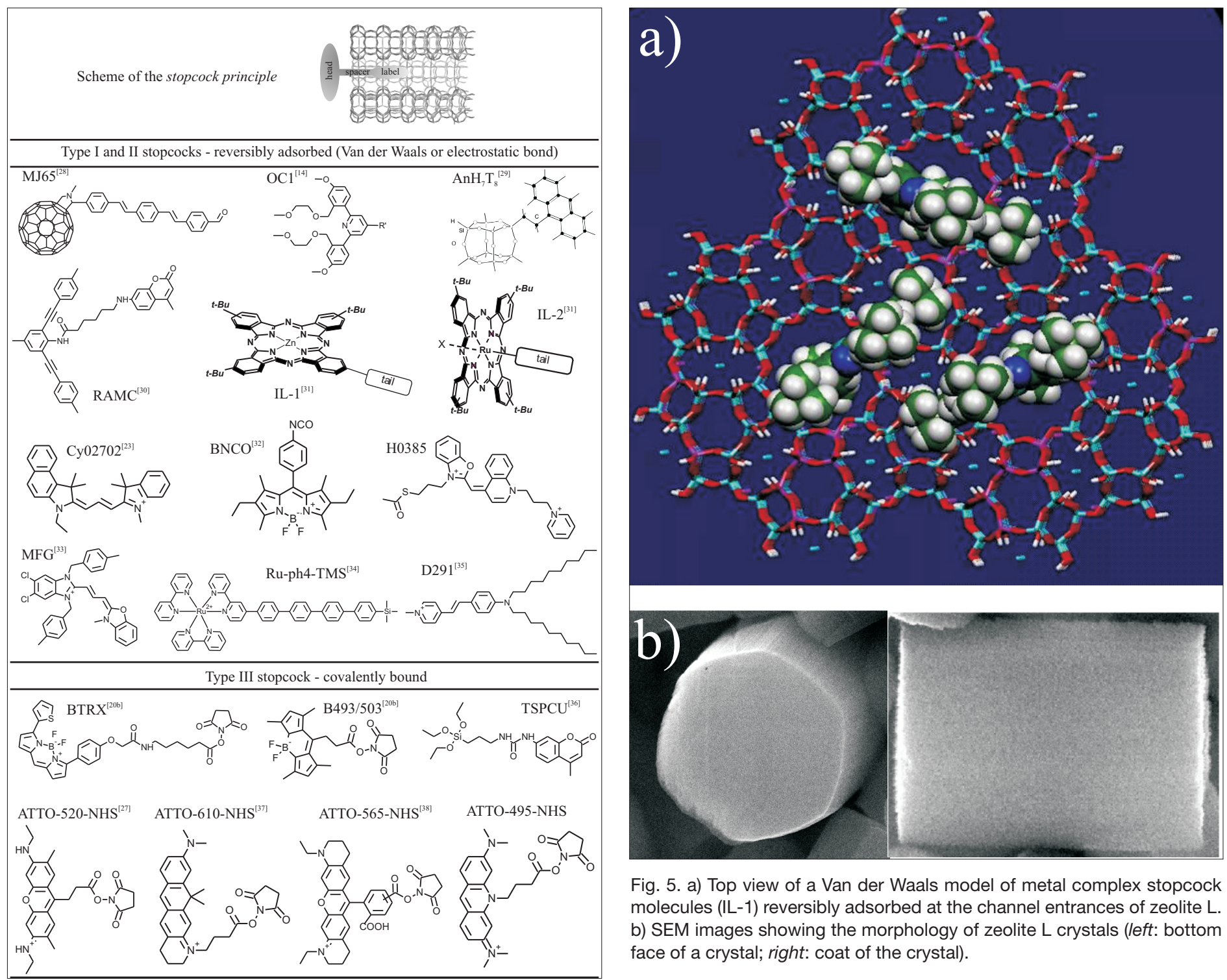

Fig. 5. a) Top view of a Van der Waals model of metal complex stopcock molecules (IL-1) reversibly adsorbed at the channel entrances of zeolite L. b) SEM images showing the morphology of zeolite L crystals (left: bottom face of a crystal; right: coat of the crystal).

Fig. 4. Stopcock molecules

at the channel entrances: the tail enters the channel, while the bulkier head cannot pass the pore entrance. The location of the stopcock can be verified experimentally by means of fluorescence microscopy, as has been shown earlier.[20,34,39] The morphology of the crystals is shown in the lower part of Fig. 5 .

\section{Interfacing}

The stopcock principle outlined above allows for the communication of dyes inside the channels with external species like a molecule, a polymer matrix, a semiconductor, a quantum sized particle, a molecular- or nano-magnet, and a biochemical or biological object. This principle is illustrated in Fig. 6 for a bidirectional and monodirectional excitation energy transport material. Linking to a biological object has been recently reported. ${ }^{[40]}$ In the following sec- tions, two other applications for stopcock mediated interfacing will be presented.

\section{Dye-sensitised Solar Cells}

Our aim is to couple the developed artificial antenna materials to organic solar cells via stopcock molecules, as sketched in Fig. 6. In a first step, an antenna material is prepared by sequentially filling the zeolite L crystals with appropriate dyes. The channel entrances are then closed with fluorescent stopcock molecules. The spectral properties of the dyes and stopcocks are precisely tuned to each other so that, upon selective excitation of the dyes inside, the energy travels via FRET to the stopcocks at the edges, but not back. ${ }^{[38]}$ Depending on whether free crystals or monolayers are used, one obtains a system where the energy transport can occur in a bidirectional (left) or in a monodirectional way (right). The stopcocks can now either re-emit this energy as fluorescence from the crystal surface, or transfer it radiationlessly to a photoelectronic or a photochemical device, labelled as 'Reaction centre' in Fig. 6.

\section{Functional Energy Transfer Labels}

Another application for stopcockplugged dye-loaded zeolite L materials is to use them as luminescent labels for analytical purposes. The working principle of a functional energy transfer label is sketched in the Scheme. The channel entrances of dye-loaded zeolite L crystals are terminated with stopcocks featuring an appropriate receptor head. This system can now bind to selected molecules or ions. Upon binding, the distance between the dyes inside of the zeolite (Dye 1) and the bound analyte is short enough for energy transfer. After selective excitation of Dye 1, the luminescence from the analyte is observed. Preliminary results show that this principle works. 


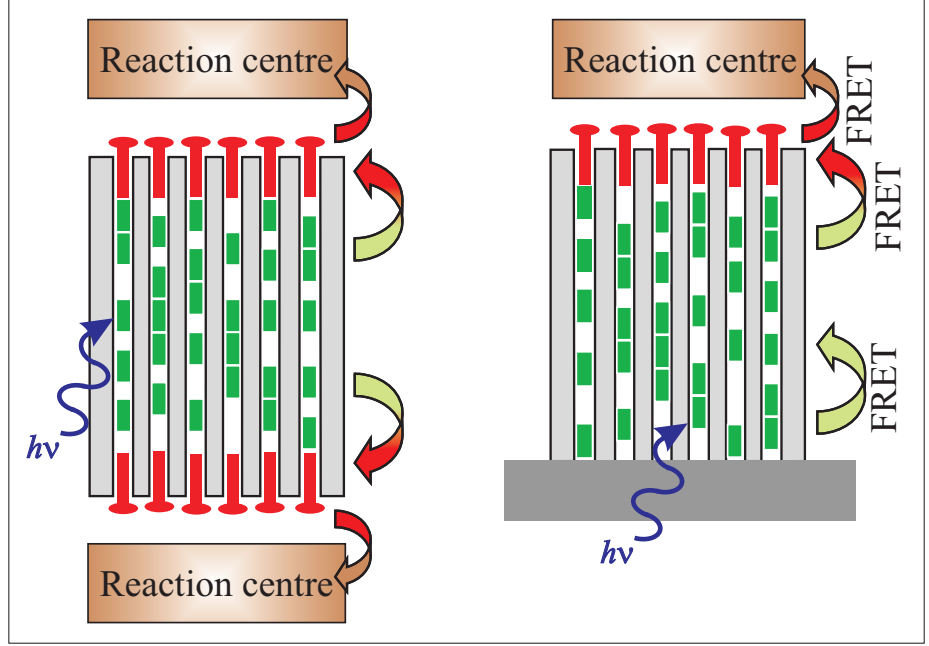

Fig. 6. Interfacing antenna materials to a reaction centre via stopcock molecules. Bidirectional (left) and monodirectional (right) energy transport materials connected to a photoelectronic or photochemical reaction centre. The excitation energy from the dyes in the channels (green rectangles) is transported via FRET to the stopcock molecules (red) located at the entrances. From there, the energy is transferred radiationlessly to a reaction centre.

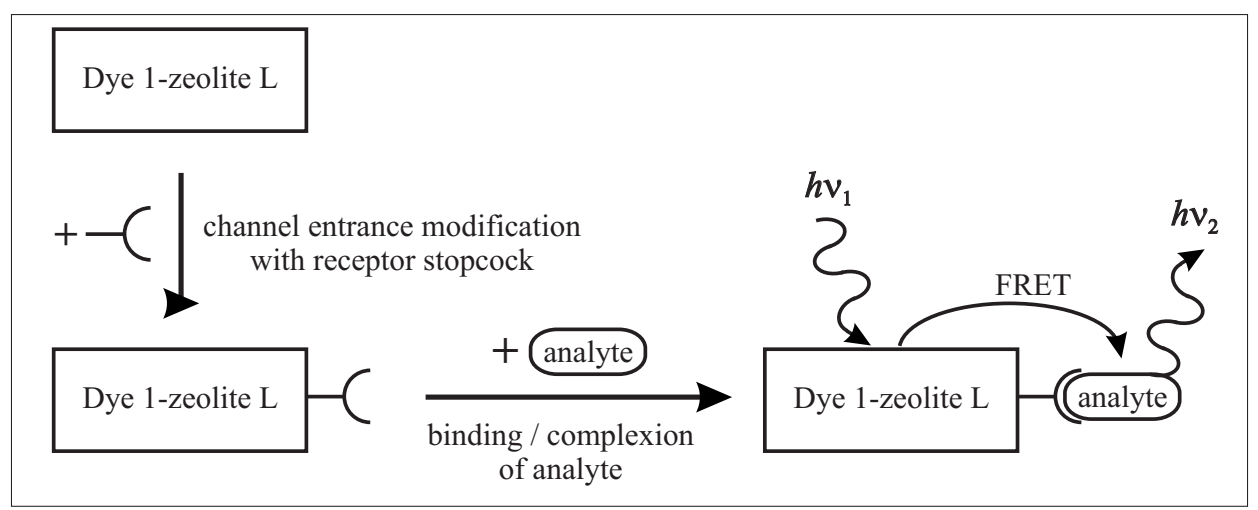

Scheme. Working principle of a functional energy transfer label. In a first step, the channel entrances of zeolite $L$ crystals, loaded with Dye 1 , are modified with a receptor stopcock. ${ }^{[27,41]}$ The resulting material can now bind to a compatible analyte, so that the distance between Dye 1 and the analyte is short enough for energy transfer to occur. recently reported. ${ }^{[25,43]}$ This work has been extended, and a synthesis procedure for transparent polymer-zeolite L materials has been developed. [24] Photographic images of a series of such hybrid materials are given in Fig. 7. All materials are transparent and exhibit the characteristic colouring of the inserted dyes.

\section{Conclusions}

Zeolite L has proven to be an ideal host material for the supramolecular organisation of molecules, complexes, and clusters. The defined geometrical constraints imposed by the channels lead to the spatial arrangement of the guest species, thereby generating highly organised materials. Further functionalities can be added by assembling such host-guest systems into well-defined macroscopic structures on various supports and by promoting communication between guests and external species or devices. The stopcock principle offers an elegant way to interface dye-loaded zeolite L crystals to other devices, such as solar cells ${ }^{[37]}$ or even biological systems. ${ }^{[40]}$ The outlined methods can be applied in the development of novel optical devices such as luminescent probes, lenses, special mirrors, filters, polarisers, grids, optical storage devices, or windows.

\section{Acknowledgements}

This work was financially supported by the Kommission für Technologische Innovation (KTI) project 2005-07, by the Schweizerisches Bundesamt für Energiewirtschaft (BFE), by the Clariant Ltd. Research Project Dye-Loaded Zeolites, and from the European Commission through the Human Potential Program (RTN 'Nanomatch', Contract No. MRTN-CT-2006035884). We would also like to thank Clariant Ltd. for providing some of the dyes used in this

\section{Transparent Dye-loaded Zeolite L Polymer Hybrid Materials}

The properties of dye-zeolite L systems outlined above make them very desirable for the development of optical hybrid materials, such as lenses, infrared plastic light-emitting diodes for use in telecommunication, dye nanostructured materials for optical data storage, or for improvement of a polymer's chemicalphysical properties. ${ }^{[42]}$ For many optical applications, the host-guest systems have to be inserted into a polymer matrix while maintaining transparency in the visible range. Drawbacks of zeolite particles are their tendency to aggregate and the pronounced light scattering in the visible range. Solubilisation and refractive index matching experiments with nanosized, dye-loaded zeolite L crystals were

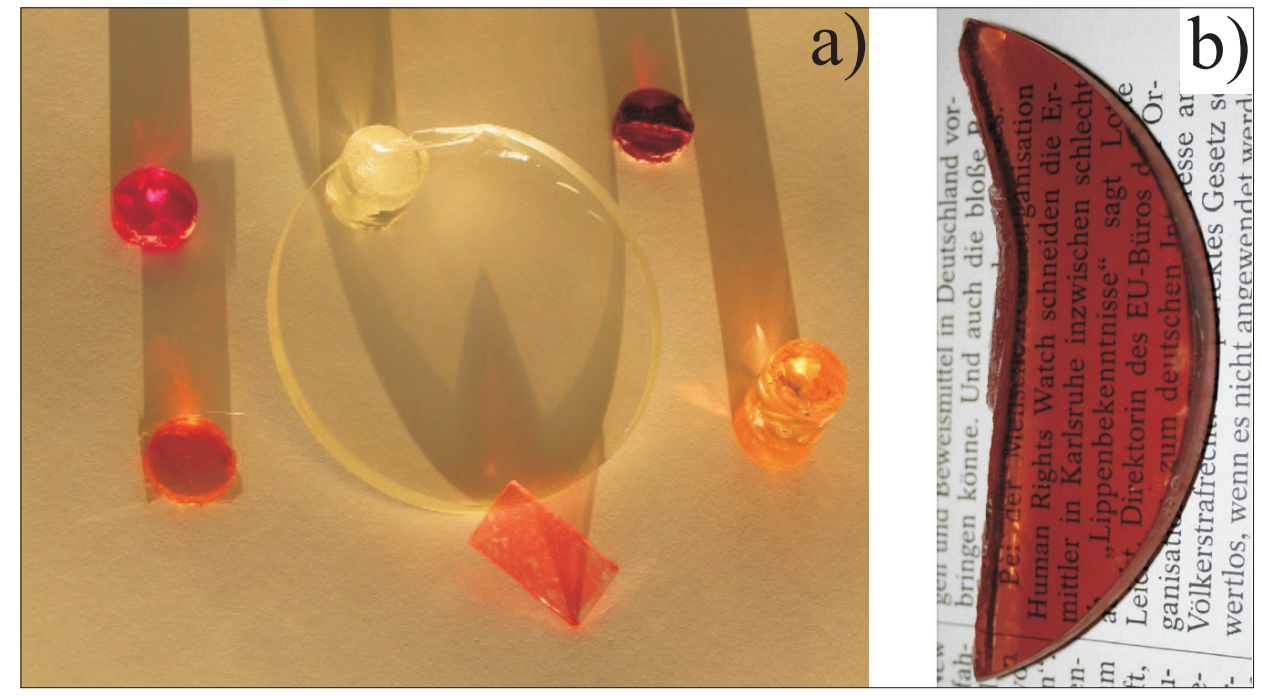

Fig. 7. Photographic images of transparent polymer-zeolite $L$ hybrid materials. a) Selection of transparent dye-loaded and unloaded zeolite L-polymer hybrid materials. b) $1 \%$ wt/wt material prepared from Ox, HY3G-zeolite L. 
work, Dr. Rodrigo Q. Albuquerque for providing Fig. 5a, and Dr. Stéphane Suárez and Dr. Dongbin Zhao for contributing to Fig. 7.

Received: June 5, 2007

[1] V. Ramamurthy, in 'Photochemistry in Organized and Constrained Media', Ed.: V. Ramamurthy, VCH publishers, New York, 1991, pp. 429-493.

[2] a) J. Schneider, D. Fanter, M. Bauer, C. Schomburg, D. Wöhrle, G. Schulz-Ekloff, Microporous Mesoporous Mater. 2000, 39, 257; b) S. Hashimoto, J. Photochem. Photobiol. C: Photochem. Rev. 2003, 4, 19; c) G. Schulz-Ekloff, D. Wöhrle, B. van Duffel, R. A. Schoonheydt, Microporous Mesoporous Mater. 2002, 51, 91; d) K. B. Yoon, Acc. Chem. Res. 2007, 40, 29; e) A. Corma, H. Garcia, Eur. J. Inorg. Chem. 2004, $6,1143$.

[3] a) C. Baerlocher, W. M. Meier, D. H. Olson, 'Atlas of Zeolite Framework Types', 5th ed., Elsevier, Amsterdam, 2001; b) T. Ohsuna, B. Slater, F. Gao, J. Yu, Y. Sakamoto, G. Zhu, O. Terasaki, D. E. W. Vaughan, S. Qiu, C. R. Catlow, Chem. Eur. J. 2004, 10, 5031; c) O. Larlus, V. P. Valtchev, Chem. Mater. 2004, 16, 3381; d) C. S. Carr, D. F. Shantz, Chem. Mater. 2005, 17, 6192.

[4] a) M. N. Chrétien, Pure Appl. Chem. 2007, 79,$1 ;$ b) F. A. Mumpton, Proc. Natl. Acad. Sci. USA 1999, 96, 3463.

[5] a) L. S. Kaanumalle, C. L. D. Gibb, B. C. Gibb, V. Ramamurthy, Org. Biomol. Chem. 2007, 5, 236; b) L. S. Kaanumalle, V. Ramamurthy, Chem. Commun. 2007, 1062.

[6] F. Hoffmann, M. Cornelius, J. Morell, M. Fröba, Angew. Chem., Int. Ed. 2006, 45 , 3216.

[7] L. Poulsen, M. Jazdzyk, J.-E. Communal, J. C. Sancho-García, A. Mura, G. Bongiovanni, D. Beljonne, J. Cornil, M. Hanack, H.-J. Egelhaaf, J. Gierschner, J. Am. Chem. Soc. 2007, 129, 8585.

[8] J. Caro, G. Finger, J. Kornatowski, J. Richter-Mendau, L. Werner, B. Zibrowius, $A d v$. Mater. 1992, 4, 273.

[9] S.L. Scandella, G. Binder, J. Gobrecht, J. C. Jansen, Adv. Mater. 1996, 8, 137.

[10] S. Megelski, A. Lieb, M. Pauchard, A. Drechsler, S. Glaus, C. Debus, A. J. Meixner, G. Calzaferri, J. Phys. Chem. B 2001, 105, 25.

[11] G. Calzaferri, N. Gfeller, J. Phys. Chem. 1992, 96, 3428.

[12] R. Beer, F. Binder, G. Calzaferri, J. Photochem. Photobiol. A: Chem. 1992, 69, 67.

[13] G. Calzaferri, N. Gfeller, J. Phys. Chem. B 1997, 101, 1396.

[14] G. Calzaferri, M. Pauchard, H. Maas, S. Huber, A. Khatyr, T. Schaafsma, J. Mater. Chem. 2002, 12, 1.

[15] a) A. Zabala Ruiz, D. Brühwiler, T. Ban, G. Calzaferri, Monatsh. Chem. 2005, 136, 77; b) Y.-J. Lee, J. S. Lee, K. B. Yoon,
Microporous Mesoporous Mater. 2005, 80, 237.

[16] U. Ciesla, F. Schüth, Microporous Mesoporous Mater. 1999, 27, 131.

[17] Y. Tanamura, T. Uchida, N. Teramae, M. Kikuchi, K. Kusaba, Y. Onodera, Nano Lett. 2001, 1, 387.

[18] H. Salmio, D. Brühwiler, J. Phys. Chem. C 2007, 111, 923 .

[19] a) G. Calzaferri, S. Huber, H. Maas, C. Minkowski, Angew. Chem., Int. Ed. 2003, 42, 3732; b) D. Brühwiler, G. Calzaferri, Microporous Mesoporous Mater. 2004, 72, 1; c) C. Minkowski, R. Pansu, M. Takano, G. Calzaferri, Adv. Funct. Mater. 2006, 16, 273.

[20] a) G. Calzaferri, US and EU patent WO 02/36490 A1, priority date 2000, granted US 2005, EU 2006; b) H. Maas, G. Calzaferri, Angew. Chem., Int. Ed. 2002, 41, 2284.

[21] C. Minkowski, G. Calzaferri, Angew. Chem., Int. Ed. 2005, 44, 5325.

[22] A. Zabala Ruiz, H. Li, G. Calzaferri, Angew. Chem., Int. Ed. 2006, 45, 5282.

[23] G. Calzaferri, S. Huber, A. Devaux, A. Zabala Ruiz, H. Li, O. Bossart, L.-Q. Dieu, Proc. of SPIE, Org. Optoelectronics and Photonics II 2006, 6192, 619216-1.

[24] S. Suárez, A. Devaux, J. Bañnuelos, O. Bossart, A. Kunzmann, G. Calzaferri, $A d v$. Func. Mater. 2007, 17, early view.

[25] S. Huber, A. Zabala Ruiz, H. Li, G. Patrinoiu, C. Botta, G. Calzaferri, Inorg. Chim. Acta 2007, 360, 869.

[26] K. Lutkouskaya, Ph. D. Thesis, University of Bern, 2007.

[27] S. Huber, G. Calzaferri, Angew. Chem., Int. Ed. 2004, 43, 6738.

[28] A. Zabala Ruiz, Ph. D. Thesis, University of Bern, 2006.

[29] C. Marcolli, G. Calzaferri, Appl. Organomet. Chem. 1999, 13, 213.

[30] A. Khatyr, H. Maas, G. Calzaferri, J. Org. Chem. 2002, 67, 6705.

[31] G. de la Torre, C. G. Claessens, T. Torres, Chem. Commun. 2007, 2000.

[32] R. Ziessel, C. Goze, G. Ulrich, M. Césario, P. Retailleau, A. Harriman, J. P. Rostron, Chem. Eur. J. 2005, 11, 7366.

[33] H. Maas, G. Calzaferri, The Spectrum 2003, 16, 18.

[34] O. Bossart, L. De Cola, S. Welter, G. Calzaferri, Chem. Eur. J. 2004, 10, 5771.

[35] O. Bossart, G. Calzaferri, Chimia 2006, $60,179$.

[36] T. Ban, D. Brühwiler, G. Calzaferri, J. Phys. Chem. B 2004, 108, 16348.

[37] G. Calzaferri, O. Bossart, D. Brühwiler, S. Huber, C. Leiggener, M. K. van Veen, A. Zabala Ruiz, C. R. Chimie 2006, 9, 214.

[38] R. Koeppe, O. Bossart, G. Calzaferri, N. S. Sariciftci, Sol. Energy Mater. Sol. Cells 2007, 91, 986.

[39] a) G. Calzaferri, S. Huber, H. Maas, C. Minkowski, Angew. Chem., Int. Ed. 2003, 42, 3732; b) S. Huber, G. Calzaferri, ChemPhysChem 2004, 5, 239.
[40] Z. Popović, M. Otter, G. Calzaferri, L. De Cola, Angew. Chem., Int. Ed. 2007, 46, 6188.

[41] H. Li, A. Devaux, Z. Popović, L. De Cola, G. Calzaferri, Microporous Mesoporous Mater. 2006, 95, 112 .

[42] a) N. Tessler, V. Medvedev, M. Kases, S. Kan, U. Banin, Science 2002, 295, 1506; b) O. Kalinina, E. Kumacheva, Chem. Mater. 2001, 13, 35; c) I. Gourevich, H. Pham, J. E. N. Jonkman, E. Kumacheva, Chem. Mater. 2004, 16, 1472; d) M. Avella, M. E. Errico, E. Martuscelli, Nano Lett. 2001, 1,1. 213; e) C. Sanchez, G. J. de A. A. Soler-Illia, F. Ribot, T. Lalot, C. R. Mayer, V. Cabuil, Chem. Mater. 2001, 13, 3061.

[43] A. Devaux, Z. Popović, O. Bossart, L. De Cola, A. Kunzmann, G. Calzaferri, Microporous. Mesoporous. Mater. 2006, 90, 69. 